\title{
Cannulation strategies in acute type A dissection repair: A systematic axillary artery approach
}

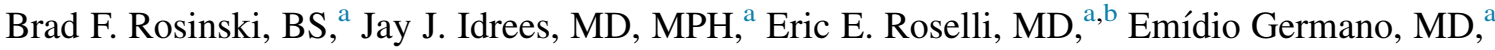 \\ Selena R. Pasadyn, BA, ${ }^{\mathrm{a}}$ Ashley M. Lowry, MS, MEd, ${ }^{\mathrm{c}}$ Eugene H. Blackstone, MD, ${ }^{\mathrm{a}, \mathrm{c}}$ \\ Douglas R. Johnston, MD, ${ }^{\mathrm{a}, \mathrm{b}}$ Edward G. Soltesz, MD, ${ }^{\mathrm{a}, \mathrm{b}}$ José L. Navia, MD, ${ }^{\mathrm{a}, \mathrm{b}}$ Milind Y. Desai, MD, \\ Stephanie L. Mick, MD, ${ }^{\mathrm{a}}$ Faisal G. Bakaeen, MD, ${ }^{\mathrm{a}, \mathrm{b}}$ and Lars G. Svensson, MD, PhD ${ }^{\mathrm{a}, \mathrm{b}}$
}

\section{ABSTRACT}

Objectives: Consensus regarding initial cannulation site for acute type A dissection repair is lacking. Objectives were to review our experience with systematic initial axillary artery cannulation, characterize patients on the basis of cannulation site, and assess outcomes.

Methods: From January 2000 to January 2017, 775 patients underwent emergency acute type A dissection repair. Initial axillary cannulation was performed in 617 $(80 \%)$, femoral in $93(12 \%)$, and central in $65(8.4 \%)$. In-hospital mortality and stroke risk factors were identified using logistic regression.

Results: Reasons for selecting initial central or femoral instead of axillary cannulation included unsuitable axillary anatomy $(\mathrm{n}=67 ; 42 \%)$, surgeon preference $(\mathrm{n}=38 ; 24 \%)$, hemodynamic instability $(\mathrm{n}=34 ; 22 \%)$, and preexisting cannulation $(\mathrm{n}=19 ; 12 \%)$. Cannulation site was shifted or added intraoperatively in $82(11 \%)$, with initial cannulation site being axillary $(n=23$ of $617 ; 3.7 \%)$, central $(6$ of $65 ; 9.2 \%)$, or femoral $(n=53$ of $93 ; 57 \%)$, for surgeon preference $(n=60 ; 73 \%)$, high flow resistance $(n=13 ; 16 \%)$, increased aortic false lumen flow $(\mathrm{n}=6 ; 7.3 \%)$, and other $(\mathrm{n}=3 ; 3.7 \%)$. In-hospital mortality was $8.6 \%(\mathrm{n}=67$; lowest for axillary, $7.3 \%[P=.02])$ and stroke $8.3 \%$ ( $\mathrm{n}=64)$. Hemodynamic instability (odds ratio [OR], 7.6; 95\% confidence interval [CI], 4.2-14), limb ischemia (OR, 3.7; 95\% CI, 1.5-9.3), stroke (OR, 5.5; 95\% CI, 2.2-14), and aortic regurgitation (OR, 2.2; 95\% CI, 1.2-4.2) at presentation were risk factors for mortality and central cannulation site $(\mathrm{OR}, 2.3 ; 95 \% \mathrm{CI}$, 1.05-5.1) and aortic stenosis (OR, 2.4; 95\% CI, 1.2-4.6) for stroke.

Conclusions: Systematic initial axillary cannulation for acute type A dissection repair is safe and effective and can be tailored to patients' specific needs. With this strategy, comparable outcomes are observed among cannulation sites and are largely determined according to patient presentation rather than cannulation site. (J Thorac Cardiovasc Surg 2019;158:647-59)

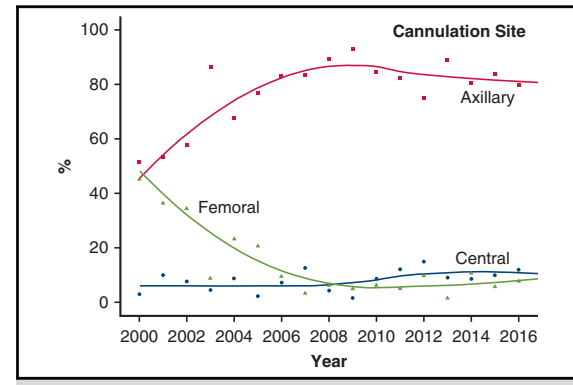

Trends in initial cannulation site over a 17-year period.

\section{Central Message}

Systematic initial axillary artery cannulation for acute type A dissection repair is safe and effective and can be tailored to a patient's specific needs.

\section{Perspective}

Systematic initial axillary artery cannulation for emergency repair of acute type A dissection is safe and effective. Selecting one cannulation site over another can be tailored to patients specific perfusion needs. When this approach to cannulation is used, comparable outcomes are observed among cannulation sites and are largely determined by the patients' presentation rather than cannulation site.

See Commentaries on pages 660,662 , and 664 .
The immediate goal of emergency acute type A dissection repair is to save a patient's life. Various cannulation strategies for its repair have been used: subclavian/axillary artery

\footnotetext{
From the Departments of ${ }^{\mathrm{a}}$ Thoracic and Cardiovascular Surgery and ${ }^{\mathrm{d}} \mathrm{Cardiovascular}$ Medicine, and ${ }^{\mathrm{b}}$ Aorta Center, Heart and Vascular Institute; and ${ }^{\mathrm{c}}$ Department of Quantitative Health Sciences, Research Institute, Cleveland Clinic, Cleveland, Ohio.

This study was funded in part by the Delos M. Cosgrove, MD, Chair for Heart Disease Research, the Dana Hamel Family Fund, the High Risk Cardiovascular Surgery Research Fund, the Gus P. Karos Registry Fund, the David Whitmire Hearst, Jr, Foundation, the Drs Sidney and Becca Fleischer Heart and Vascular Education Chair, the Haslam Family Endowed Chair in Cardiovascular Medicine, and the Sheikh Hamdan bin Rashid Al Maktoum Distinguished Chair in Thoracic and Cardiovascular Surgery.
}

(axillary), femoral artery (femoral), and ascending aorta or proximal aortic arch (central) are the most common. ${ }^{1-4}$ Each offers distinct advantages and limitations. ${ }^{1,5-7}$ Our

Read at the 98th Annual Meeting of The American Association for Thoracic Surgery, San Diego, California, April 28-May 1, 2018.

Received for publication April 27, 2018; revisions received Oct 17, 2018; accepted for publication Nov 14, 2018; available ahead of print Feb 13, 2019.

Address for reprints: Lars G. Svensson, MD, PhD, Cleveland Clinic, Heart and Vascular Institute, 9500 Euclid Ave/Desk J4-1, Cleveland, OH 44915 (E-mail: svenssl@ccf.org).

0022-5223/ $\$ 36.00$

Copyright $(\subset) 2019$ Published by Elsevier Inc. on behalf of The American Association for Thoracic Surgery

https://doi.org/10.1016/j.jtcvs.2018.11.137 


\section{Abbreviations and Acronyms \\ $\mathrm{CT}=$ computed tomography \\ IRAD $=$ International Registry of Acute Aortic Dissections \\ STS $=$ The Society of Thoracic Surgeons \\ TEE $=$ transesophageal echocardiography}

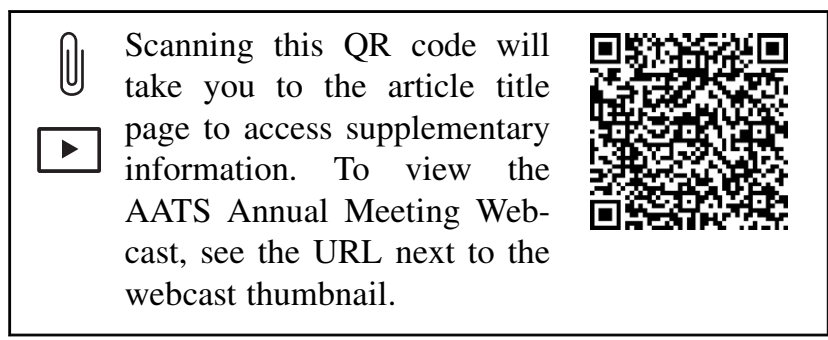

strategy has evolved to a systematic initial axillary artery cannulation approach, ${ }^{2}$ the results of which are the focus of this study.

Crawford and DeBakey first used the subclavian artery for arterial inflow for ventricular assist device implantation ${ }^{6}$ (for purposes of this study, subclavian and axillary artery cannulation are not distinguished ${ }^{8,9}$ ). This and other studies, including our own, have shown that axillary cannulation is safe and effective. ${ }^{8-11}$ It offers the advantage of antegrade perfusion, but can be time-consuming and might not be anatomically feasible because of involvement by the dissection. Alternatively, central or femoral cannulation can save time and might be preferred for hemodynamically unstable patients. Similar to axillary artery cannulation, central cannulation provides antegrade perfusion ${ }^{12,13}$; however, it can potentiate propagation of dissection, clot embolization, or rupture. Femoral cannulation can also be rapidly instituted, ${ }^{14,15}$ but subjects patients to possible detrimental effects of retrograde blood flow and might not provide brain perfusion because of a flutter valve effect. Thus, opinions currently vary regarding optimal cannulation site. Our practice evolved to a systematic historical axillary artery cannulation approach for managing acute type A dissection (Video 1 ). ${ }^{3}$ Initial femoral or central cannulation has typically been selected when axillary cannulation is not the ideal choice or when the patient's presentation indicates preference for another site.

Guidelines regarding the most appropriate selection of cannulation site are limited by lack of granular detail. Therefore, objectives of the present study were to review our experience with acute type A dissection repair in an era when initial axillary artery cannulation evolved into a systematic approach, characterize patients on the basis of cannulation site, and assess mortality and morbidity of the dissection repair according to initial cannulation site.

\section{METHODS}

From January 2000 to January 2017, 775 patients underwent acute type A dissection repair at Cleveland Clinic. At presentation, dissection extent was DeBakey type I in $667(86 \%)$ and type II in $100(13 \%$; Table 1; type not stated in 8$)$. Thirty-two patients $(4.1 \%)$ were in heart failure or cardiogenic shock, $22(2.8 \%)$ were being resuscitated from cardiac arrest, $72(9.3 \%)$ presented with aortic rupture and $88(11 \%)$ with tamponade, and 311 $(40 \%)$ had a pericardial effusion. Presence of shock or new-onset heart failure, cardiac arrest, rupture, or tamponade at presentation constitute what we call preoperative hemodynamic instability. ${ }^{1}$ In addition, renal failure was present in $48(6.3 \%)$, and $36(4.6 \%)$ presented with stroke. These and all other data used in this study were approved for use in research by the Cleveland Clinic institutional review board, with individual patient consent waived.

\section{Dissection Repair}

Limited repair with ascending aorta or hemiarch replacement was performed in 597 patients $(77 \%)$. An extended repair with total arch replacement or a conventional or frozen elephant trunk procedure was performed in 178 patients $(23 \%$; Table 2$) .{ }^{16}$

\section{Clinical Outcomes}

Primary outcomes were in-hospital mortality and stroke. Secondary outcomes were spinal cord infarction, renal failure, respiratory failure requiring tracheostomy, bowel ischemia, reoperation for bleeding, and intensive care unit and postoperative lengths of stay.

For stroke, spinal cord infarction, and renal failure, only new postoperative events were considered as complications. Postoperative stroke was characterized using Valve Academic Research Consortium-2 criteria. ${ }^{17}$ Spinal cord infarction was defined as occurrence of postoperative weakness or paralysis confirmed as spinal cord infarction on imaging. All other outcomes were defined using the Society of Thoracic Surgeons definitions (see http://www.sts.org/sts-national-database/database-managers/adultcardiac-surgery-database/data-collection).

\section{Data Analysis}

All analyses were performed using SAS statistical software (SAS version 9.4; SAS Institute, Cary, NC) and R programming. ${ }^{18}$

\section{Deviations From Systematic Axillary Cannulation}

We tabulated and extensively reviewed the reasons for departing from initial axillary artery cannulation. We also reviewed shifts from or additions to the initial cannulation site in the course of dissection repair.

\section{Multivariable Analysis of Outcomes}

Multivariable logistic regression analysis was used to identify risk factors associated with in-hospital mortality and stroke. Variables considered in these models are listed in Table E1. To meet model assumptions, linearizing transformations of ordinal and continuous variable scales were added into variable selection. A $P$ value criterion of .05 was used for retention of variables in the model. Variable selection used bagging (bootstrap aggregation $)^{19,20}$ with automated forward stepwise analysis of 1000 resampled data sets. Variables appearing in at least $50 \%$ of analyses were considered reliably statistically significant and included in final models. ${ }^{21}$

\section{Missing Data}

To account for missing values for some variables in multivariable modeling, we performed 5-fold multiple imputation using a Markov chain Monte Carlo technique. ${ }^{22}$

\section{Presentation}

Categorical variables are summarized as frequencies and percentages and were compared using the $\chi^{2}$ test, or Fisher's exact test when fewer 
TABLE 1. Patient characteristics and presentation

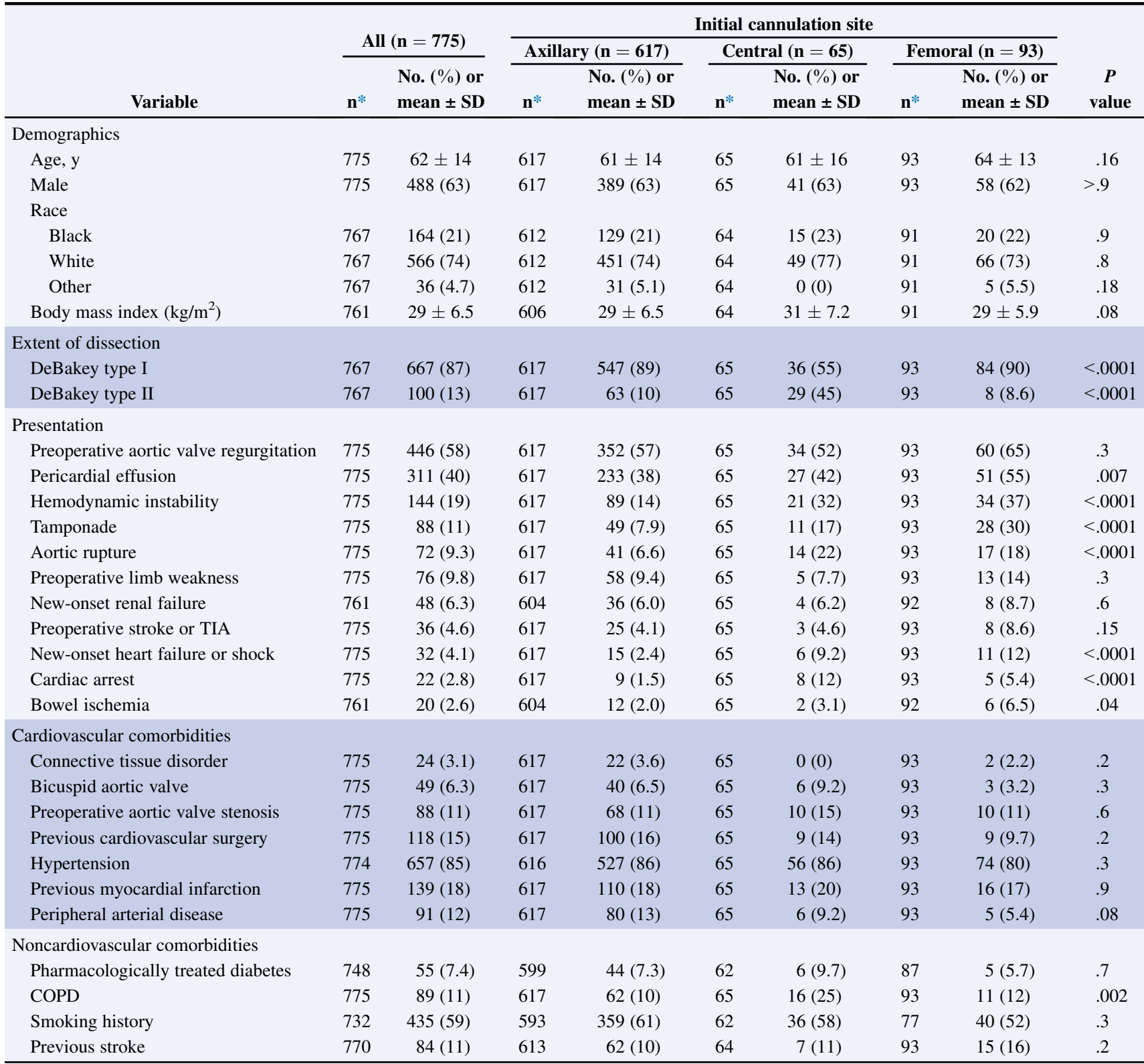

$S D$, Standard deviation; TIA, transient ischemic attack; COPD, chronic obstructive pulmonary disease. *Patients with data available.

than 5 events were observed in either group. Continuous variables are summarized as mean \pm standard deviation or equivalently as 15 th, 50 th (median), and 85th percentiles when their distribution was skewed, but all were compared using the Wilcoxon rank sum test to account conservatively for non-normality of distributions. Trends are displayed using a smoothing spline (R statistical software). ${ }^{23}$

\section{RESULTS}

\section{Initial Cannulation Sites for Acute Type A Dissection Repair}

Over the 17-year study period, site used for initial cannulation was axillary in $614(79 \%)$, femoral in $92(12 \%)$, and central in $65(8.4 \%)$. In 4 patients $(0.52 \%)$, initial cannulation of 2 sites was used (axillary and femoral in 2, axillary and central in 1, and femoral and central in 1). For analysis, the 2 axillary and femoral and 1 axillary and central cases were included in the initial axillary cannulation group, and the single femoral and central case was included in the initial femoral group. Preference for initial cannulation site evolved. Early in the experience, initial axillary as well as femoral cannulation were frequently performed (Figure 1). Between 2000 and 2008, a sharp decline in use of initial femoral cannulation was accompanied by a complementary sharp increase in use of initial axillary 
TABLE 2. Operative details

\begin{tabular}{|c|c|c|c|c|c|c|c|c|c|}
\hline \multirow[b]{3}{*}{ Detail } & \multirow{2}{*}{\multicolumn{2}{|c|}{ All $(n=775)$}} & \multicolumn{6}{|c|}{ Initial cannulation site } & \multirow[b]{3}{*}{$P$ value } \\
\hline & & & \multicolumn{2}{|c|}{ Axillary $(n=617)$} & \multicolumn{2}{|c|}{ Central $(n=65)$} & \multicolumn{2}{|c|}{ Femoral $(\mathbf{n}=93)$} & \\
\hline & $\mathbf{n}^{*}$ & Value & $\mathbf{n}^{*}$ & Value & $\mathbf{n}^{*}$ & Value & $\mathbf{n}^{*}$ & Value & \\
\hline Cannulation shift & 775 & $82(11)$ & 617 & $23(3.7)$ & 65 & $6(9.2)$ & 93 & $53(57)$ & $<.0001$ \\
\hline Extended repair & 775 & $178(23)$ & 617 & $152(25)$ & 65 & $17(26)$ & 93 & $9(9.7)$ & .005 \\
\hline Aortic valve replacement & 775 & $206(27)$ & 617 & $171(28)$ & 65 & $15(23)$ & 93 & $20(22)$ & .4 \\
\hline Aortic valve resuspension & 775 & $322(42)$ & 617 & $257(42)$ & 65 & $16(25)$ & 93 & $49(53)$ & .002 \\
\hline Aortic valve repair & 775 & $45(5.8)$ & 617 & $34(5.5)$ & 65 & $7(11)$ & 93 & $4(4.3)$ & .18 \\
\hline Root replacement & 775 & $165(21)$ & 617 & $131(21)$ & 65 & $17(26)$ & 93 & $17(18)$ & .5 \\
\hline Circulatory arrest & 775 & 744 (96) & 617 & $604(98)$ & 65 & $51(78)$ & 93 & 89 (96) & $<.0001$ \\
\hline Total circulatory arrest time, $\min \dagger$ & 744 & $0 / 20 / 35$ & 604 & $0 / 20 / 36$ & 51 & $0 / 13 / 29$ & 89 & $9 / 23 / 36$ & .002 \\
\hline Brain perfusion & 775 & $580(75)$ & 617 & $474(77)$ & 65 & $38(58)$ & 93 & $68(73)$ & .005 \\
\hline Retrograde & 775 & $505(65)$ & 617 & $409(66)$ & 65 & $30(46)$ & 93 & $66(71)$ & .002 \\
\hline Antegrade & 775 & $58(7.5)$ & 617 & $51(8.3)$ & 65 & $6(9.2)$ & 93 & $1(1.1)$ & .04 \\
\hline Antegrade and retrograde & 775 & $15(1.9)$ & 617 & $12(1.9)$ & 65 & $2(3.1)$ & 93 & $1(1.1)$ & .7 \\
\hline CABG & 775 & $150(19)$ & 617 & $124(20)$ & 65 & $13(20)$ & 93 & $13(14)$ & .4 \\
\hline Total myocardial ischemic time, min & 768 & $93 \pm 46$ & 613 & $94 \pm 46$ & 63 & $99 \pm 50$ & 92 & $85 \pm 44$ & .06 \\
\hline Total CPB time, min & 775 & $157 \pm 59$ & 617 & $159 \pm 58$ & 65 & $157 \pm 64$ & 93 & $148 \pm 57$ & .07 \\
\hline
\end{tabular}

Data are presented as No. $(\%)$ or mean \pm standard deviation except where otherwise noted. $C A B G$, Coronary artery bypass grafting; $C P B$, cardiopulmonary bypass. *Patients with data available. $\dagger 15$ th $/ 50$ th/ 85 th percentiles.

cannulation. From 2008 through 2016, initial axillary cannulation became standard practice and initial femoral or central cannulation was performed selectively. More recently, initial central cannulation has modestly increased by needling the true lumen using transesophageal echocardiography (TEE) guidance and feeding in a cannulation wire.

The acute dissection was more extensive (DeBakey type I) in the axillary and femoral cannulation groups than in the central cannulation group ( $89 \%$ vs $90 \%$ vs $55 \%$, respectively, $P<.001$; Table 1 ). Unlike the axillary group, patients who had initial central or femoral cannulation had a more severe presentation, with a higher proportion presenting with hemodynamic instability $(14 \%$ vs $32 \%$ vs $37 \%$, respectively; $P<.001)$. Patients who had axillary or central cannulation had more extended repairs than those with femoral cannulation ( $25 \%$ vs $26 \%$ vs $9.7 \%$, respectively; $P=.005$; Table 2).

\section{Reasons for Initial Non-Axillary Artery Cannulation}

Among the 158 patients $(20 \%)$ in whom the axillary artery was not the initial cannulation site, unsuitability or inaccessibility for axillary cannulation was due to dissection or thinned vessel wall in 56 of $67(84 \%)$ and obesity in 11 of 67 (16\%; Table E2). Among the remaining 91 , reasons for nonaxillary cannulation were surgeon preference $(\mathrm{n}=38,24 \%)$, hemodynamic instability $(\mathrm{n}=34$; $22 \%)$, and cannulation existing before dissection $(\mathrm{n}=19$; $12 \%$ ), such as in the setting of an iatrogenic dissection $(n=18)$ or previous use of extracorporeal membrane oxygenation $(\mathrm{n}=1)$; shifting to a different cannulation site was deemed unnecessary in these situations.

\section{Shifting of Cannulation Site}

In most patients $(n=693 ; 89 \%)$, the initial cannulation site was maintained throughout the operation, but in 82 $(11 \%)$ it was shifted to a different site (Table 3 and Figure 2). This was most often the case for initial femoral cannulation $(\mathrm{n}=53 ; 65 \%)$, which was shifted to a new site after the cooling phase, mostly to central cannulation

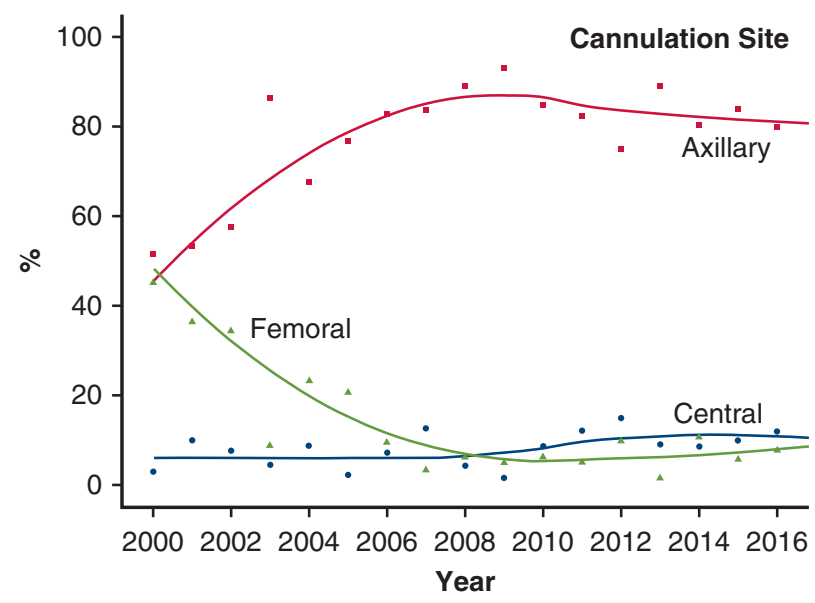

FIGURE 1. Temporal trend of selection of initial cannulation sites. Solid lines are smoothing spline curves, and symbols represent percentage of patients with the stated cannulation site each year. 
TABLE 3. Indications for intraoperative cannulation shifting or adding

\begin{tabular}{lcccc}
\hline \multicolumn{1}{c}{ Indication } & Total $(\mathbf{n}=\mathbf{8 2})$ & Cannulation site \\
\cline { 3 - 5 } Shifted or added site & & & Central $(\mathbf{n}=\mathbf{6}[\mathbf{7 . 3} \% \mathbf{0})$ & Femoral $(\mathbf{n}=\mathbf{5 3}[\mathbf{6 5} \% \mathbf{0})$ \\
$\quad$ Axillary & $1(1.2)$ & $0(0)$ & $1(17)$ & $0(0)$ \\
Femoral & $8(10)$ & $5(22)$ & $2(33)$ & $1(1.9)$ \\
Central & $70(85)$ & $18(78)$ & $0(0)$ & $52(98)$ \\
Brachiocephalic & $2(2.4)$ & $0(0)$ & $2(33)$ & $0(0)$ \\
Multiple & $1(1.2)$ & $0(0)$ & $1(17)$ & $0(0)$ \\
Reason for shift or add & & & $3(50)$ & $51(96)$ \\
Surgeon preference & $60(73)$ & $6(26)$ & $1(17)$ & $1(1.9)$ \\
High perfusion resistance & $13(16)$ & $11(48)$ & $1(17)$ & $0(0)$ \\
Aortic false lumen flow & $6(7.3)$ & $5(22)$ & $1(17)$ & $1(1.9)$ \\
Other & $3(3.7)$ & $1(4.3)$ & & \\
\hline
\end{tabular}

Data are presented as No. $(\%)$.

( $\mathrm{n}=52 ; 98 \%)$. In the central group, cannulation site was shifted in $6(7.3 \%): 2$ to the brachiocephalic artery, 2 to femoral, 1 to axillary, and 1 to axillary and femoral. In the axillary group, cannulation site was shifted in 23 $(28 \%)$ : to central in 18 and femoral in 5 .

The most common reasons for shifting cannulation sites were surgeon preference $(n=60 ; 73 \%)$ or detection of high resistance to blood flow on cardiopulmonary bypass $(\mathrm{n}=13 ; 16 \%$; Table 3$)$. Figure 2 shows the fate of the cannulation site when the initial cannulation was axillary, femoral, or central, and Tables E3 and E4 show a comparison of patient characteristics and intraoperative details among those with and without a shift in cannulation site.

\section{In-Hospital Outcomes}

In-hospital mortality was $8.6 \%(n=67$; Table 4). Mortality was lower in the axillary and central cannulation groups than in the femoral group, and this has continued over the experience ( $7.3 \%$ vs $11 \%$ vs $16 \%$, respectively; $P=.02$; Figure E1, $A$ ). Risk factors for mortality included presence of moderate to severe aortic regurgitation, hemodynamic instability, stroke at presentation, and limb weakness at presentation (Table 5).

Unadjusted risk of stroke was similar across initial cannulation sites $(7.6 \%$ axillary vs $14 \%$ central vs $8.6 \%$ femoral, respectively, $P=.2$; Figure E1, $B$ ). However, in multivariable analysis, risk of stroke was associated with use of central cannulation and presence of aortic stenosis; this association was possibly more common without brain perfusion during circulatory arrest (Table E5), but numbers are small.

\section{Trends in Hospital Morbidity}

Other in-hospital complications included spinal cord infarction $(\mathrm{n}=5 ; 0.65 \%)$, renal failure requiring dialysis $(\mathrm{n}=73 ; 9.6 \%)$, which was constant over the experience (Figure E1,C), respiratory failure requiring tracheostomy
( $\mathrm{n}=104 ; 13 \%$ ), which declined gradually over the experience (Figure E1, D), bowel ischemia ( $\mathrm{n}=15$; $1.9 \%)$, and reoperation for bleeding $(\mathrm{n}=69 ; 8.9 \%$; Table 4). Occurrence of these comorbidities was similar regardless of whether or not the patient presented with hemodynamic instability (Table E6), and whether or not the cannulation site was shifted (Tables E7 and E8).

\section{DISCUSSION \\ Principal Findings}

Review of our 17-year experience with acute type A dissection repair indicates that a systematic, initial axillary artery cannulation approach was feasible in most patients and was found to be generally safe in the context of this high-risk patient population and an effective strategy for cannulation. In the early part of the experience, initial femoral cannulation was more commonly used, but with growing experience, initial axillary artery cannulation became standard, such that by 2016, axillary/subclavian artery cannulation was used in approximately $90 \%$ of cases. A small proportion of patients were initially cannulated at an alternative site (femoral or central), the most common reason being anatomic unsuitability of the axillary artery. However, outcomes among the various cannulation groups were comparable. The main risk factor for mortality was hemodynamic instability at presentation. This suggests that acute outcomes are associated with the underlying disease and its sequelae at presentation and that at experienced centers, choice of cannulation site might not importantly affect mortality.

Interestingly, use of central cannulation was associated with higher occurrence of stroke. It is possible that this association is related to intraoperative adjunctive techniques, such as variable use of brain perfusion during circulatory arrest or morphologic variability among patients having branch vessel involvement in the dissection. The scope of this study was such that we did not have precise 

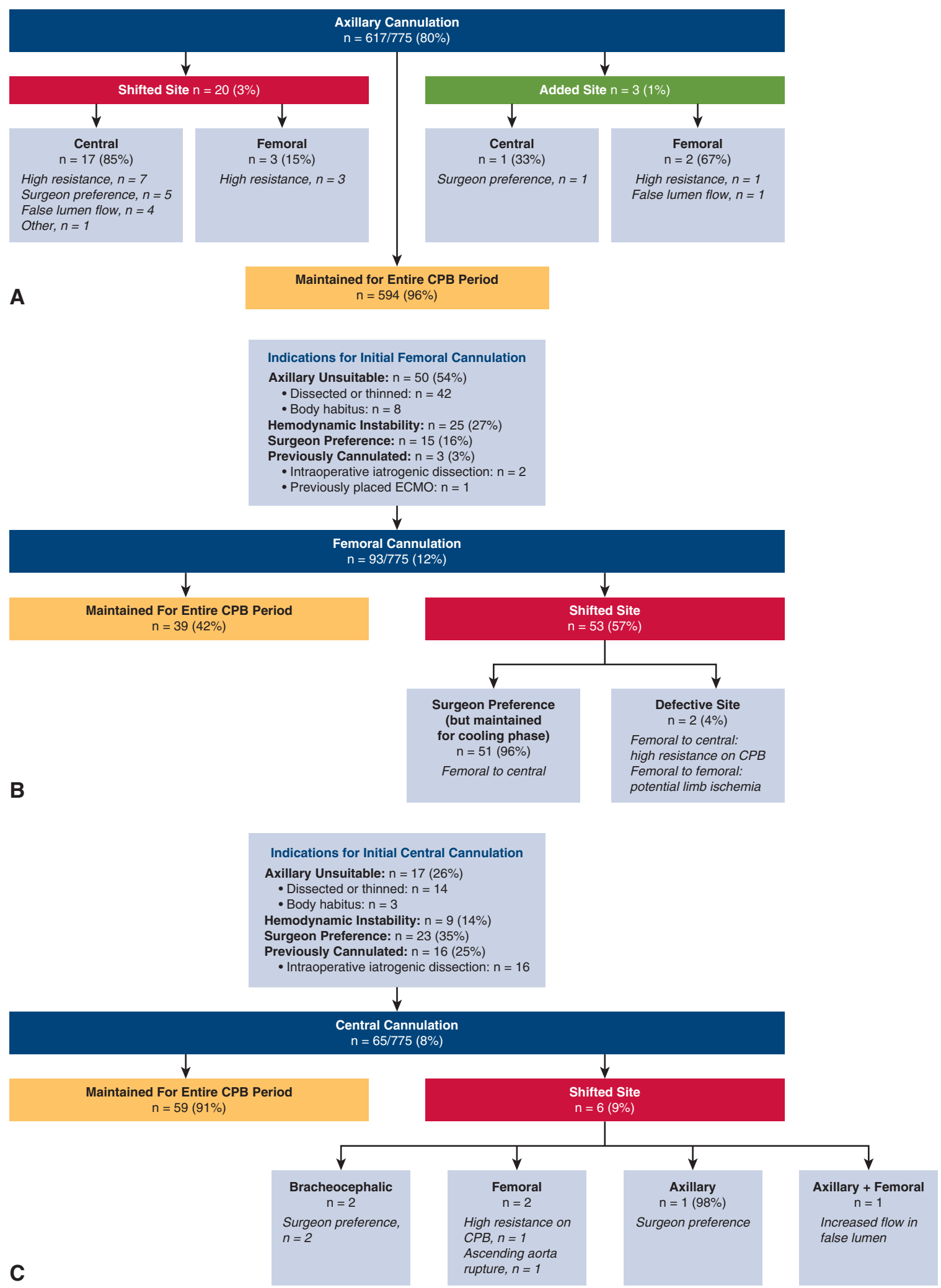

FIGURE 2. Consolidated Standards of Reporting Trials-style diagrams for patients in each initial cannulation group. A, Fate of initial axillary artery cannulation. B, Indications for initial femoral artery cannulation and fate. C, Indications for initial central cannulation and fate. $C P B$, Cardiopulmonary bypass, $E C M O$, extracorporeal membrane oxygenation. 
TABLE 4. In-hospital outcomes

\begin{tabular}{|c|c|c|c|c|c|c|c|c|c|}
\hline \multirow[b]{3}{*}{ Outcome } & \multirow{2}{*}{\multicolumn{2}{|c|}{ All $(n=775)$}} & \multicolumn{6}{|c|}{ Initial cannulation site } & \multirow[b]{3}{*}{$P$ value } \\
\hline & & & \multicolumn{2}{|c|}{ Axillary $(n=617)$} & \multicolumn{2}{|c|}{ Central $(n=65)$} & \multicolumn{2}{|c|}{ Femoral $(n=93)$} & \\
\hline & $\mathbf{n}^{*}$ & Value & $\mathbf{n}^{*}$ & Value & n* & Value & $\mathbf{n}^{*}$ & Value & \\
\hline Hospital death & 775 & $67(8.6)$ & 617 & $45(7.3)$ & 65 & $7(11)$ & 93 & $15(16)$ & .02 \\
\hline Stroke & 775 & $64(8.3)$ & 617 & $47(7.6)$ & 65 & $9(14)$ & 93 & $8(8.6)$ & .2 \\
\hline Disabling stroke & 775 & $41(5.3)$ & 617 & $28(4.5)$ & 65 & $7(11)$ & 93 & $6(6.5)$ & .09 \\
\hline Renal failure requiring dialysis & 760 & $73(9.6)$ & 604 & $53(8.8)$ & 63 & $8(13)$ & 93 & $12(13)$ & .3 \\
\hline Spinal cord infarction & 775 & $5(0.65)$ & 617 & $5(0.81)$ & 65 & $0(0)$ & 93 & $0(0)$ & .5 \\
\hline Respiratory failure requiring tracheostomy & 775 & $104(13)$ & 617 & $77(12)$ & 65 & $10(15)$ & 93 & $17(18)$ & .3 \\
\hline Bowel ischemia & 775 & $15(1.9)$ & 617 & $11(1.8)$ & 65 & $2(3.1)$ & 93 & $2(2.2)$ & .8 \\
\hline Reoperation for bleeding & 775 & $69(8.9)$ & 617 & $52(8.4)$ & 65 & $6(9.2)$ & 93 & $11(12)$ & .6 \\
\hline ICU length of stay, $\mathrm{h} \dagger$ & 775 & $40 / 95 / 364$ & 617 & $39 / 94 / 356$ & 65 & $42 / 90 / 444$ & 93 & $39 / 125 / 397$ & .7 \\
\hline Postoperative length of stay, $\mathrm{d} \dagger$ & 775 & $6.1 / 10 / 24$ & 617 & $6.1 / 10 / 23$ & 65 & $6.7 / 11 / 27$ & 93 & $5.7 / 10 / 27$ & .4 \\
\hline
\end{tabular}

Data are presented as No. (\%) except where otherwise noted. ICU, Intensive care unit. *Patients with data available. $\nmid 15$ th/50th/85th percentiles.

imaging details about branch vessel involvement. Further research characterizing these postoperative strokes and their cause is necessary to identify the underlying mechanism. This will be important because in recent years, many institutions have adopted central cannulation as their standard strategy. A better understanding of the interplay between patient morphology and cannulation site might drive the selection of initial site.

\section{Findings in Context}

The present study is important because it reports outcomes of a large number of patients who presented with varying complexity of acute type A aortic dissection and who were managed at a high-volume center using a systematic cannulation approach that was tailored when it appeared necessary. In a recent publication by the International Registry of Acute Aortic Dissections (IRAD) on outcomes over the past decade, mortality was
$12.7 \%,{ }^{24}$ whereas other experienced centers have reported mortality comparable to ours $(8.6 \%)$, in the range of $7.7 \%$ to $17 \% .^{24-26}$ A 2018 publication using the Society of Thoracic Surgeons national database reported mortality of $17 \% .^{4}$ The reasons for better outcomes are likely multifactorial.

\section{Assessing the Systematic Axillary Strategy to Cannulation}

The safety and effectiveness of axillary cannulation during various cardiac and aortic procedures have been well described. Most previous studies have evaluated use of axillary cannulation in an elective setting. ${ }^{5,8,10}$ A few have examined its use during acute type A dissection, including comparisons with other cannulation sites, ${ }^{13,15}$ but the preoperative planning and intraoperative implementation that occurs during treatment of acute type A dissection is a dynamic process. Choice of initial

TABLE 5. Risk factors for in-hospital mortality and stroke

\begin{tabular}{lccc}
\hline \multicolumn{1}{c}{ Risk factor } & Estimate \pm SE & P value & \\
\hline Mortality & & .005 & 71 \\
Race other than black or white & $1.3 \pm 0.47$ & .01 & 56 \\
Aortic valve regurgitation & $0.81 \pm 0.32$ & $<.0001$ & 97 \\
Presented with hemodynamic instability & $2.0 \pm 0.30$ & .0003 & 70 \\
Presented with stroke or TIA & $1.7 \pm 0.47$ & .005 \\
Limb ischemia & $1.3 \pm 0.46$ & $<.0001$ \\
Longer CPB time, hours & $0.70 \pm 0.13$ & & 53 \\
Stroke & & .01 & 99 \\
Smaller body mass index $\dagger$ & $-1.7 \pm 0.67$ & .009 \\
Aortic valve stenosis & $0.87 \pm 0.34$ & .006 \\
No hyperlipidemia & $-0.80 \pm 0.29$ & .03 \\
No root replacement & $-0.89 \pm 0.42$ & .04 \\
Central cannulation without shifting & $0.83 \pm 0.40$ & 71 \\
\hline
\end{tabular}

$S E$, Standard error; $T I A$, transient ischemic attack; $C P B$, cardiopulmonary bypass. *Proportion of 1000 bootstrap models in which variable appeared with $P \leq .05$. $\dagger \mathrm{Ln}($ body mass index), natural logarithmic transformation. 
cannulation site varies according to disease morphology, quality of access vessels, patient stability, and surgeon preference. Maintaining perfusion throughout an operation commonly involves shifting to another inflow site based on adequacy of flow, perceptions about quality of perfusion, and alterations in the patient's vascular anatomy during the course of the operation. No previous studies on cannulation in acute type A dissection have explored using axillary cannulation as part of an overall systematic cannulation strategy during these complex operations.

In this study, we have shown that using axillary cannulation as a principal element of a systematic cannulation strategy is feasible, safe, and effective for most acute type A dissections. Using the axillary artery for inflow offers the advantages of maintaining antegrade true lumen blood flow during and after the cooling period and provides a source for unilateral antegrade brain perfusion during circulatory arrest, potentially decreasing the risk of stroke. Use of axillary cannulation did not independently change the risk for stroke.

\section{Tailoring the Cannulation Site to Fit Patient Needs}

The present study is novel because we captured detailed information regarding the decision-making process behind selecting one cannulation site over another in the context of a systematic approach. Flexibility in the choice of cannulation site was necessitated by the patient's presentation and anatomic characteristics. In some, the axillary artery was anatomically unsuitable for cannulation and thus was not selected. In others, patient presentation and characteristics dictated the preference for femoral or central arterial cannulation.

One of the main limitations of axillary artery cannulation is time. When performed routinely, however, axillary cannulation can be performed efficiently. We estimate that it adds only 15 to 30 minutes to total operative time, but we could not adequately assess that with the data available. In hemodynamically unstable patients, we typically forgo axillary cannulation in favor of central or femoral cannulation.

Because of the time-saving potential it provides, central cannulation has more recently been used as a first choice, although that subgroup of patients is not adequately represented in this data set because this is a recent trend. We have been careful to select central cannulation as a primary choice using clinical and imaging characteristics to assess the safety of this approach. In general, we might select central cannulation first when performing a primary sternotomy and when the true lumen looks to be easily accessible with a needle from the anterior wall of the aorta on TEE or computed tomography imaging. With advanced intraoperative TEE imaging used in concert with perioperative analysis of 3-D reconstruction from computed tomography,

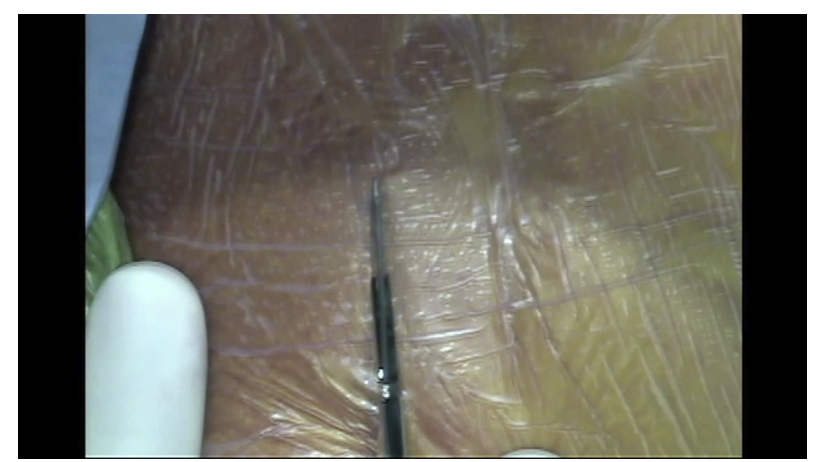

VIDEO 1. Axillary cannulation procedure. Video available at: https:// www.jtcvs.org/article/S0022-5223(18)33416-0/fulltext.

we find the true lumens of the distal ascending aorta and arch to be consistently accessible and do not routinely use epiaortic echocardiography to guide central access. With intraoperative TEE, we are also able to consistently identify the course of the access wire within the true lumen distal to the puncture site, which confirms the safety of central cannulation. For patients requiring redo sternotomy, those with particularly complex-looking dissection morphology, or when the surgeon prefers it, axillary cannulation is the default approach. A potential advantage of axillary artery cannulation is avoidance of manipulating the acutely dissected ascending aorta, minimizing risk of rupture and proximal or distal extension of the dissection. ${ }^{13}$

For those who become hemodynamically unstable, the choice is between central and femoral cannulation. If the mechanism of instability is early tamponade, the patient will likely benefit from a quick sternotomy and pericardiotomy to relieve the pressure. If he or she is then stabilized, we quickly reassess the adequacy of each cannulation site. If the ascending aorta looks reasonable to cannulate using a modified Seldinger technique, we will likely use central cannulation. If not, and the patient remains stable, we might expose the axillary artery or defer to use of the femoral artery.

For the most unstable patients undergoing cardiopulmonary resuscitation, there might not be adequate time to perform a full skin preparation. In these situations, the simplest approach is initial femoral artery cannulation to stabilize the patient for the ensuing extensive operation. A well-described limitation of femoral perfusion in patients with acute dissection is uncertainty of downstream endorgan perfusion related to reversal of aortic flow in the acutely dissected state. For this reason, when femoral cannulation has been used as the initial site, it is rarely maintained as the inflow site for the entire operation, particularly because continued use of femoral perfusion can disrupt the distal anastomosis. Thus, most often, the cannulation is shifted to central in the graft after performing the distal aortic anastomosis with the patient under circulatory arrest. 
For some patients, the central or femoral artery was the initial site of cannulation because they were already cannulated via that route when the type A dissection occurred intraoperatively. Only in a quarter of patients who deviated from axillary cannulation as the initial site was a central or femoral cannulation site chosen because of surgeon preference. The latter represent the subset of patients operated on during the early part of the experience, when femoral artery cannulation was relatively common. It is important to note that even in the earlier experience, the cannulation site was shifted in most patients from femoral to central after the distal aortic anastomosis. Initial use of femoral cannulation can be an effective bridging strategy, particularly when patients are severely hemodynamically compromised and swift initiation of cardiopulmonary bypass is paramount for successful rescue. ${ }^{24,27}$

A shift in cannulation site was also required in a small proportion of patients who were initially cannulated via the axillary artery. These decisions were driven by changes in flow occurring intraoperatively, likely due to changes in morphology. Typically, the perfusionist notes a sudden rise in resistance through the axillary inflow, suggesting that a change has occurred in the patient's condition. If this happens after the distal aortic anastomosis is completed, the cannulation is shifted to central in the graft. If it occurred during the cooling phase, the shift may be central or femoral. These data suggest that cannulation sites can also be used interchangeably, depending on the patient's morphology and ongoing assessment of adequacy of flow. We found that cannulationsite shifting only modestly influenced outcomes. This practice most likely optimizes conduct of the operation, but because of the relatively small sample size, we recommend that shifting be used sparingly in select patients.

\section{Clinical Implications}

At our institution, several initiatives have led to improvements in care of patients presenting with acute type A dissection. By developing a dedicated, multidisciplinary emergency response team of cardioaortic specialists, the care pathway for treating these patients has been streamlined, resulting in improved accuracy in diagnosis and prompt decisions about surgical intervention, minimizing the time from presentation to operating room. In an increasing proportion of patients, time saved by improving efficiency allowed us to initiate early treatment, before their clinical condition irreversibly deteriorated. Thus, for many patients, we were able to accommodate complex procedures when feasible and necessary. We believe that our axillary-first approach to cannulation was an important aspect of improved surgical care. Implementing this strategy as a standard has likely translated into improved outcomes in part by appropriate selection of patients for alternative cannulation site and shifting of site. It is possible that in select patients, minimizing use of femoral or central cannulation might have prevented complications and contributed to improved outcomes. For example, with the axillary artery cannulated, if the aorta ruptures or the patient decompensates on opening the chest, "sucker" cardiopulmonary bypass can be initiated.

\section{Limitation}

Findings from this study must be interpreted in the context of its limitations. Although the current analysis is based on a large cohort of patients with acute type A dissection, it represents a single institution experience at a high-volume center; this limits generalizing findings to other settings. Because of the preoperative differences among the cannulation groups and our institution's systematic use of initial axillary cannulation, safety and effectiveness of one cannulation strategy over another should be interpreted within this context. Further, because of the observational nature of the study, the reasons behind surgeon preferences for selecting cannulation site could not be fully ascertained in all cases. As the initial cannulation strategy evolved early in the study period, there was nonsystematic selection of cannulation site, which limits interpretation of the findings. Inferences about nonaxillary cannulation are tentative because of the selective use of these alternatives. This includes brachiocephalic cannulation, which also provides antegrade initial perfusion. ${ }^{28}$

\section{CONCLUSIONS}

In the setting of acute type A dissection repair, initial axillary cannulation is safe, effective, and can be tailored to specific patient characteristics, demonstrating the feasibility of this cannulation site in most patients. When this strategy is instituted at experienced high-volume centers, outcomes are influenced predominantly by patients' presenting condition rather than the cannulation site used. Although central cannulation was associated with a higher occurrence of postoperative stroke, this relationship is likely multifactorial rather than directly causative. Further characterization of all strokes after repair is needed, especially as more institutions accept central cannulation as their standard.

\section{Webcast}

You can watch a Webcast of this AATS meeting presentation by going to: https://aats.blob.core.windows. net/media/18Apr29/20ABC $\% 202$.Adult $\%$ 20Cardiac $\% 20$ SS \%20(PM)/S51\%20-\%20Part\%202/S51_2.mp4.

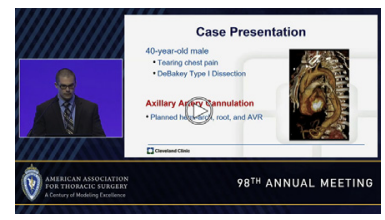




\section{Conflict of Interest Statement}

Authors have nothing to disclose with regard to commercial support.

The authors thank Patrick R. Vargo, MD, and Brian Kohlbacher for creating the video.

\section{References}

1. Svensson LG, Crawford ES, Hess KR, Coselli JS, Safi HJ. Dissection of the aorta and dissecting aortic aneurysms. Improving early and long-term surgical results. Circulation. 1990;82:IV24-38.

2. Svensson LG, Crawford ES, Hess KR, Coselli JS, Raskin S, Shenaq SA, et al. Deep hypothermia with circulatory arrest. Determinants of stroke and early mortality in 656 patients. J Thorac Cardiovasc Surg. 1993;106:19-31.

3. Hussain ST, Svensson LG. Surgical techniques in type A dissection. Ann Cardiothorac Surg. 2016;5:233-5.

4. Lee TC, Kon Z, Cheema FH, Grau-Sepulveda MV, Englum B, Kim S, et al. Contemporary management and outcomes of acute type A aortic dissection: an analysis of the STS adult cardiac surgery database. J Card Surg. 2018;33:7-18.

5. Svensson LG, Blackstone EH, Rajeswaran J, Sabik JF III, Lytle BW, GonzalezStawinski G, et al. Does the arterial cannulation site for circulatory arrest influence stroke risk? Ann Thorac Surg. 2004;78:1274-84.

6. DeBakey ME. Left ventricular bypass pump for cardiac assistance. Clinical experience. Am J Cardiol. 1971;27:3-11.

7. Frederick JR, Yang E, Trubelja A, Desai ND, Szeto WY, Pochettino A, et al. Ascending aortic cannulation in acute type a dissection repair. Ann Thorac Surg. 2013;95:1808-11.

8. Sabik JF, Lytle BW, McCarthy PM, Cosgrove DM. Axillary artery: an alternative site of arterial cannulation for patients with extensive aortic and peripheral vascular disease. J Thorac Cardiovasc Surg. 1995;109:885-91.

9. Sabik JF, Nemeh H, Lytle BW, Blackstone EH, Gillinov AM, Rajeswaran J, et al. Cannulation of the axillary artery with a side graft reduces morbidity. Ann Thorac Surg. 2004; 77:1315-20.

10. Svensson LG, Nadolny EM, Penney DL, Jacobson J, Kimmel WA, Entrup MH, et al. Prospective randomized neurocognitive and S-100 study of hypothermic circulatory arrest, retrograde brain perfusion, and antegrade brain perfusion for aortic arch operations. Ann Thorac Surg. 2001;71:1905-12.

11. El-Hamamsy I, Ouzounian M, Demers P, McClure S, Hassan A, Dagenais F, et al. State-of-the-art surgical management of acute type A aortic dissection. Can J Cardiol. 2016;32:100-9.

12. Reece TB, Tribble CG, Smith RL, Singh RR, Stiles BM, Peeler BB, et al. Central cannulation is safe in acute aortic dissection repair. J Thorac Cardiovasc Surg. 2007; 133:428-34.

13. Sabashnikov A, Heinen S, Deppe AC, Zeriouh M, Weymann A, Slottosch I, et al. Axillary or aortic cannulation for aortic repair in patients with Stanford A dissection? Ann Thorac Surg. 2016;102:787-94.

14. Kamiya H, Kallenbach K, Halmer D, Ozsoz M, Ilg K, Lichtenberg A, et al. Comparison of ascending aorta versus femoral artery cannulation for acute aortic dissection type A. Circulation. 2009;120:S282-6.

15. Klotz S, Heuermann K, Hanke T, Petersen M, Sievers HH. Outcome with peripheral versus central cannulation in acute type A dissection. Interact Cardiovasc Thorac Surg. 2015;20:749-53.

16. Svensson LG, Rushing GD, Valenzuela ES, Rafael AE, Batizy LH, Blackstone EH, et al. Modifications, classification, and outcomes of elephanttrunk procedures. Ann Thorac Surg. 2013;96:548-58.

17. Kappetein AP, Head SJ, Genereux P, Piazza N, van Mieghem NM, Blackstone EH, et al. Updated standardized end point definitions for transcatheter aortic valve implantation: the Valve Academic Research Consortium-2 consensus document (VARC-2). Eur J Cardiothorac Surg. 2012;42:S45-60.

18. R Development Core Team. R: A Language and Environment for Statistical Computing. Version 3.4.2 (2016-06-21). Vienna, Austria: R Foundation for Statistical Computing; 2016. Available at: http://www.R-project.org. Accessed April 19, 2018.

19. Sauerbrei W, Schumacher M. A bootstrap resampling procedure for model building: application to the Cox regression model. Stat Med. 1992;11:2093-109.

20. Rajeswaran J, Blackstone EH. Identifying risk factors: challenges of separating signal from noise. J Thorac Cardiovasc Surg. 2017;153:1136-8.

21. Breiman L. Bagging predictors. Mach Learn. 1996;24:123-40.
22. Rubin DB. Multiple Imputation for Non-response in Surveys. New York: Wiley; 1987.

23. Ripley BD, Maechler MR. Fit a smoothing spline. Available at: http://stat.ethz ch/R-manual/R-patched/library/stats/html/smooth.spline.html.

24. Bossone E, Gorla R, LaBounty TM, Suzuki T, Gilon D, Strauss C, et al. Presenting systolic blood pressure and outcomes in patients with acute aortic dissection. J Am Coll Cardiol. 2018;71:1432-40.

25. Andersen ND, Benrashid E, Ross AK, Pickett LC, Smith PK, Daneshmand MA, et al. The utility of the aortic dissection team: outcomes and insights after a decade of experience. Ann Cardiothorac Surg. 2016;5:194-201.

26. Beller JP, Scheinerman JA, Balsam LB, Ursomanno P, DeAnda A Jr. Operative strategies and outcomes in type A aortic dissection after the enactment of a multidisciplinary aortic surgery team. Innovations (Phila). 2015;10:410-5.

27. Conzelmann LO, Weigang E, Mehlhorn U, Abugameh A, Hoffmann I, Blettner M, et al. Mortality in patients with acute aortic dissection type A: analysis of pre- and intraoperative risk factors from the German Registry for Acute Aortic Dissection Type A (GERAADA). Eur J Cardiothorac Surg. 2016;49: e44-52.

28. Preventza O, Price MD, Spiliotopoulos K, Amarasekara HS, Cornwell LD, Omer S, et al. In elective arch surgery with circulatory arrest, does the arterial cannulation site really matter? A propensity score analysis of right axillary and innominate artery cannulation. J Thorac Cardiovasc Surg. 2018;155:1953-60.

Key Words: DeBakey type I dissection, cardiopulmonary bypass cannulation

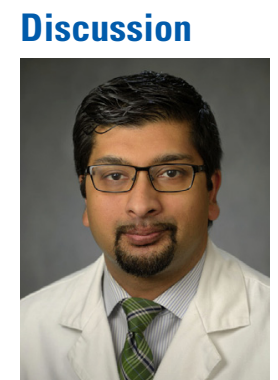

Dr Nimesh D. Desai (Philadelphia, $P a)$. Thank you and appreciate the invitation from the AATS to discuss this paper and be able to read the manuscript in advance, which was very well written. I congratulate you, Brad, on doing a fantastic job up there as a medical student. Outstanding work.

The Cleveland Clinic has long advocated the use of axillary cannulation over femoral cannulation in the setting of acute aortic dissection, and this has made the practice of open surgery for type A dissection safer, and we learned from this experience throughout the world. In your study, again, I think you have shown that femoral cannulation is probably not as optimal a strategy as axillary cannulation, but we do take issue with the comment and the outcome that central cannulation may be more related to stroke.

At Penn, our approach is to perform central cannulation routinely, but this has to be done in a specific way, with the Seldinger technique, TEE guidance, and a long femoral type cannula which is placed over a wire, always in the true lumen and always with image guidance, and this is really critical to making sure that you avoid these potential neurologic issues with direct aortic cannulation in type A dissection. We believe there is no better or faster way to re-expand the true lumen and stop malperfusion syndromes and actually fix the problem that led to their development.

Combining the Penn experience and the Pittsburgh experience with Tom Gleason, who uses the same technique, we have actually looked at over 700 cases that have been 
cannulated with direct aortic cannulation with a stroke rate of between $4 \%$ and $6 \%$, certainly comparable with the current series. In the manuscript you provided, in this series the central cannulation patients were $20 \%$ more likely to receive no circulatory arrest, which means they were done with a clamped distal anastomosis, and in those that had circulatory arrest, a large proportion did not receive any cerebral protection strategy during the surgery; they only had straight hypothermic circulatory arrest.

So I would argue that your paper really suggests that a clamped dissection repair and doing a dissection repair without cerebral perfusion is probably disadvantageous to the patient, not direct aortic cannulation.

I have 3 questions. First, can you please describe the technique of direct aortic cannulation used and how often you were able to verify that the true lumen was cannulated with that technique? Number 2, can you speculate on why direct cannulation cases were less likely to receive an open distal repair or cerebral protection during the circ arrest period? And then finally, and this is potentially the most important confounder, how do you manage dissected supra-aortic vessels when you are going on bypass? If the patient has a dissected innominate and right carotid artery, are they more likely to get aortic cannulation? Is there more supra-aortic vessel involvement in the patients who had direct aortic cannulation?

And please feel free to defer some of these questions to your senior mentors who are here, and again, congratulations on an outstanding paper.

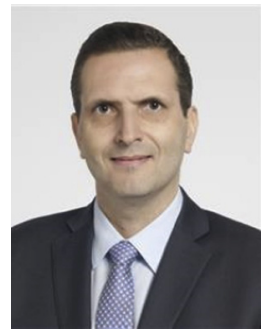

Dr Faisal G. Bakaeen (Cleveland, Ohio). I see Dr Svensson heading to the microphone. Eric was getting ready to go, too.

Dr Lars G. Svensson (Cleveland, Ohio). Well, Brad, why don't you start off and see what you think.

Dr Desai. The technique of cannulating the aorta directly during acute dissections.

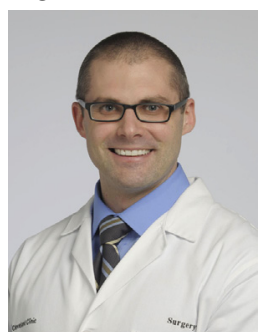

Mr Brad F. Rosinski (Cleveland, Ohio). Typically the surgeon's specific technique was not recorded and did not note whether the Seldinger technique was used or not. I reviewed the central cannulation patients specifically for that.

Dr Svensson. Okay. Brad, the second question.

Dr Desai. Why central aortic cannulation cases were less likely to receive an open distal repair or cerebral perfusion.

Mr Rosinski. Many of these patients had a DeBakey type II dissection that was more localized to the proximal ascending, so the distal repair did not need to extend to the innominate or further. So you could do these repairs with the cross-clamp on.
Dr Svensson. Great questions. And, look, we have been debating both at the aorta meeting, as you know, and also here today how best to cannulate these patients. I think the important point is, despite the numbers and our previous studies, we really have not been able to show any major difference in mortality according to where the cannulation occurs. The paper from the STS in the Journal of Cardiac Surgery suggests there may be some differences, but the difference seems to be maybe in stroke.

And so getting back to your question, the initial way we manage patients, even if they had a slightly low blood pressure, is to cannulate the subclavian with the idea that if a patient ruptures when we open the chest, we can go on to pump suction and manage patients that way.

As far as central cannulation and the patients who had central cannulation, more recently we have been using the Seldinger technique. It's something that Eric Roselli has been very keen on, particularly doing it together with frozen elephant trunks in the hybrid rooms. As we have moved into hybrid rooms using TEE and now obviously with radiographic screening, we can do that more accurately. So that is something we have been doing more often as a sort of modification.

The other thing that Brad didn't mention, and he knows the data probably better than anybody else, is that some of these patients were intraoperative dissections who started off with central cannulation. So there is a small group of those that he mentioned offhand.

As far as what to do in patients who have compromise of the greater vessels and arch, that is a very good question, and I don't think any of us have a good solution to it. We know that if you cannulate the femorals, you can have that flutter valve effect; Joe Coselli was talking about that earlier. We have seen patients who, when you do EEG monitoring, the EEG goes flat and you think you have done fine, but in fact you haven't perfused the brain because of that flutter valve effect.

With the subclavian artery, axillary artery, some of those patients you can get by and cool them. The other option is just to go straight into central cannulation, put cannulas up the greater vessels, and then perfuse them. And then as we have discussed in the aorta meeting with many people's input, a lot of those patients, especially young people, you do individual bypasses to those greater vessels. I think the key to that group of patients, though, is, at least the way I have always done it, I try and perfuse both lumens. So just like as we discussed the descending aorta in chronic dissections and to some extent acute dissections, if you are not sure which lumen perfuses the brain, which is always the critical part, try and perfuse both of them. But I don't think we have the absolute answer on which technique is better in those complex patients. 


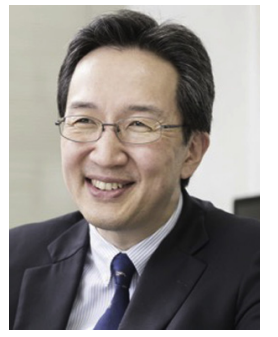

Dr Tohru Asai (Otsu, Japan). I enjoyed the great paper by a smart medical student. I could see the future of the AATS.

I have 2 simple questions. Between the subgroups of 3 cannulation groups, there must be some other differences in baseline characteristics. What I really want to know is the incidence of perioperative dissection of the arch vessels. Arch vessels sometimes are pretty much separated in severe cases, and have you taken a look at the incidence of epiaortic branch dissection in each group?

Mr Rosinski. Yes, we did collect those data. We just didn't report it in this study, but it's something that we maybe could report in the revision.

Dr Asai. For example, did the central cannulation group have a higher incidence of arch vessel dissection? That's one thing I want to know.

Mr Rosinski. Okay, thank you.

Dr Bakaeen. I see that Eric is at microphone 2, and I know that you have developed a simplified approach to most of those patients. Eric, do you want to comment?

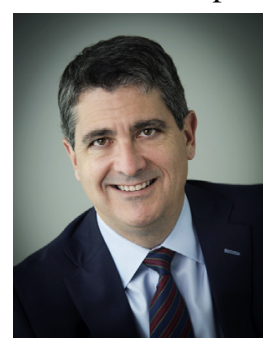

Dr Eric Roselli (Cleveland, Ohio). I just wanted to add to Brad's response to your question, because I think it's a good question. Based on the great work that Brad and the team have done creating a robust and granular database of these patients, we will be able to answer some of those questions with more detail.

I would like to make some comments on the importance of arch branch dissection. Understanding this issue requires more than just asking the binary question of whether the vessel is dissected or not, because we know many times we see those branch vessels are dissected and it isn't a clinical problem. In our subsequent analyses we will be looking further into that specific question and how it relates to neurologic symptoms at the time of presentation. Our database will allow us to look closely at specifics like the extent of dissection. By performing more detailed imaging analysis, we will be looking along the length of those vessels to understand how the true and false lumen is perfused in each of those vessels, and I think that kind of detail has a bigger impact on the outcome. So when we see a patient with dissection in those branch vessels, we now spend more time looking closely at the CAT scan and the specific characteristics of those vessels to gain some understanding of what's happening with flow. If the false lumen looks like it has thrombus in it, it's a much more worrisome finding than if the vessel itself is dissected. But both lumens look patent. This affects our strategy, and those patients are the ones we want to cannulate sooner rather than later.
We have learned from the team at Penn, and thank you for showing us that direct central cannulation is a good, safe, and fast technique. We are using central cannulation more often in primary cases. And we have also learned from the Pittsburgh group that you alluded to from Tom Gleason's work that we should have a lower threshold to cut down on the patient's carotid arteries and reconstruct the distal vessel if we need to optimize perfusion of the brain. We need to get better at managing the patients with brain malperfusion.

Dr Asai. Thank you for answering. Another simple question then. Epiaortic scanning every single case for our dissection we use for direct cannulation. You mentioned transesophageal echo, which was considered to have the blind spot sometimes, and is the epiaortic scanning routinely used in your facility?

Dr Svensson. We used to use it routinely, but we have moved away from that, doing it on every single patient; we rely more on TEE. But I think that's a reasonable thing if you have the setup to do it on every case, which we do. But our anesthesiologists have not been as enthusiastic as they used to be on the epiaortics.

Dr Roselli. And if I could add to that, we have also been satisfied with TEE to see the wire in the true lumen when we are doing central cannulation. It works really well to image the aorta beyond the cannulation site, so the blind spot you speak about is not an issue. We also are careful to use the preoperative CT scan imaging to guide the location for needle access when performing central cannulation.

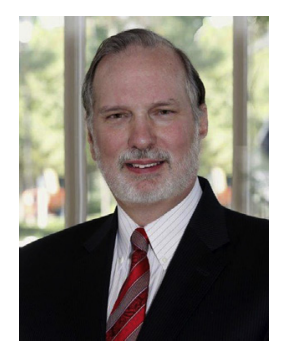

Dr Joseph E. Bavaria (Philadelphia, $P a)$. First of all, again, a super job by a medical student under harsh conditions, especially dissection. I want to come at it a little bit on a different point. We at Penn and Pittsburgh and other places, especially in Europe, have gone through the maturation process or an evolution process from femoral to axillary, and then we have gone from axillary now to central almost ubiquitously as an evolution.

But one of the reasons is because we want to stay in the chest and make this operation faster as far as getting in, taking care of business, making sure that the times that patients have malperfusion are lower.

So this question is about, have you analyzed femoral versus axillary versus central regarding the time, from the time they get on bypass and get the case started, in other words, a time of operation or conduct of operation modality? Have you looked at that?

And the second question is a really technical simple one, which is, the patients who were, say, femorally cannulated and then went to central cannulation as a strategy, because 
that is what we used to do, are they femoral cannulation or are they central cannulation cases in your database?

Mr Rosinski. To answer your second question, in the overall comparison we included those patients in the femoral group because we went off of what the initial -

Dr Svensson. Intention to treat.

Mr Rosinski. Yes. And then to answer your other question, we did not look at the time from presentation to getting on cardiopulmonary bypass or when patients set foot in the hospital, but that could be something we could look into in the future.

Dr Svensson. So, Joe, just to answer the first part of your question, we are pretty efficient in getting patients into the operating room, and then the first thing that the resident, fellow, or associate starts doing is dissecting out the axillary subclavian artery and sewing the side graft, because it takes the attending maybe 30 or 45 minutes to get in. So while they are tapping, the patient is getting prepared for the procedure. Obviously if you open the chest right away and the patient ruptures, then you are in kind of a difficult position. And so that's also one of the reasons why we've evolved the way we do it, particularly because we transfer a lot of patients straight into the OR, and if we are not sure about the diagnosis, then it also gives us some time to do the TEE and make sure that there is actually aortic dissection.

But great questions and lots of things that we need to answer from this database that Brad has put together. Thank you. 

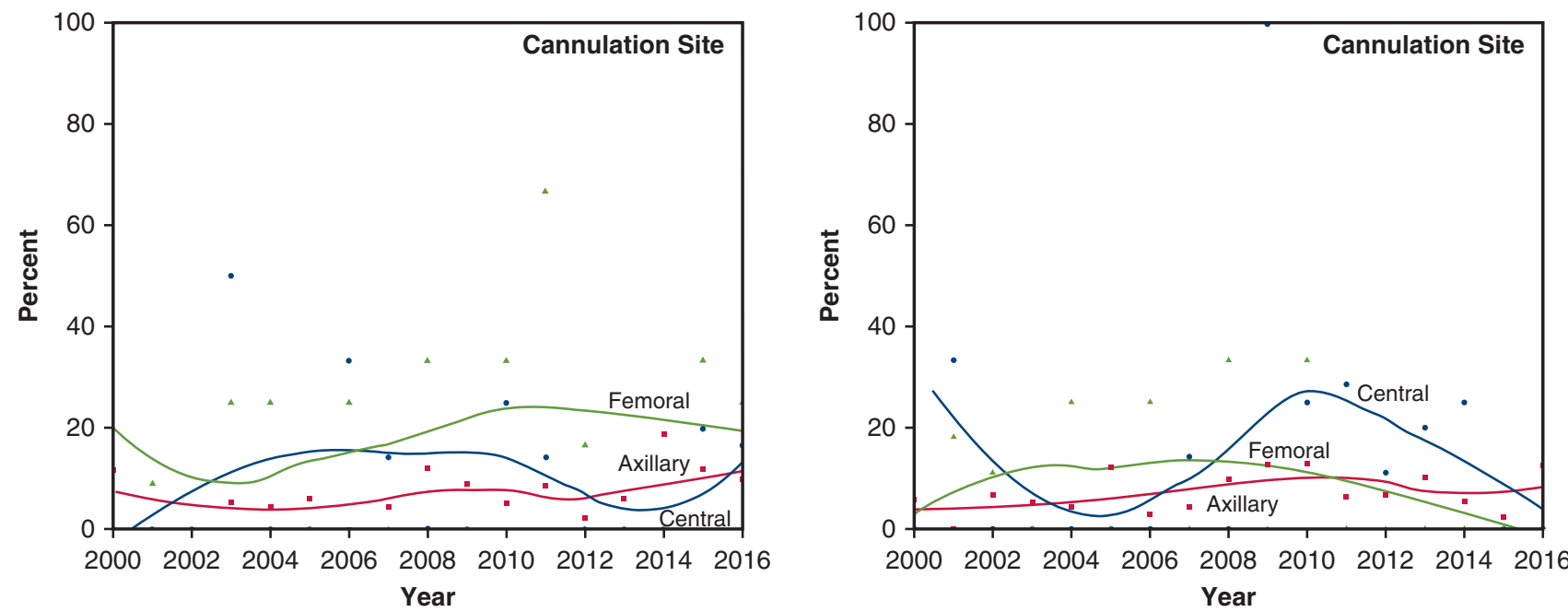

A

B
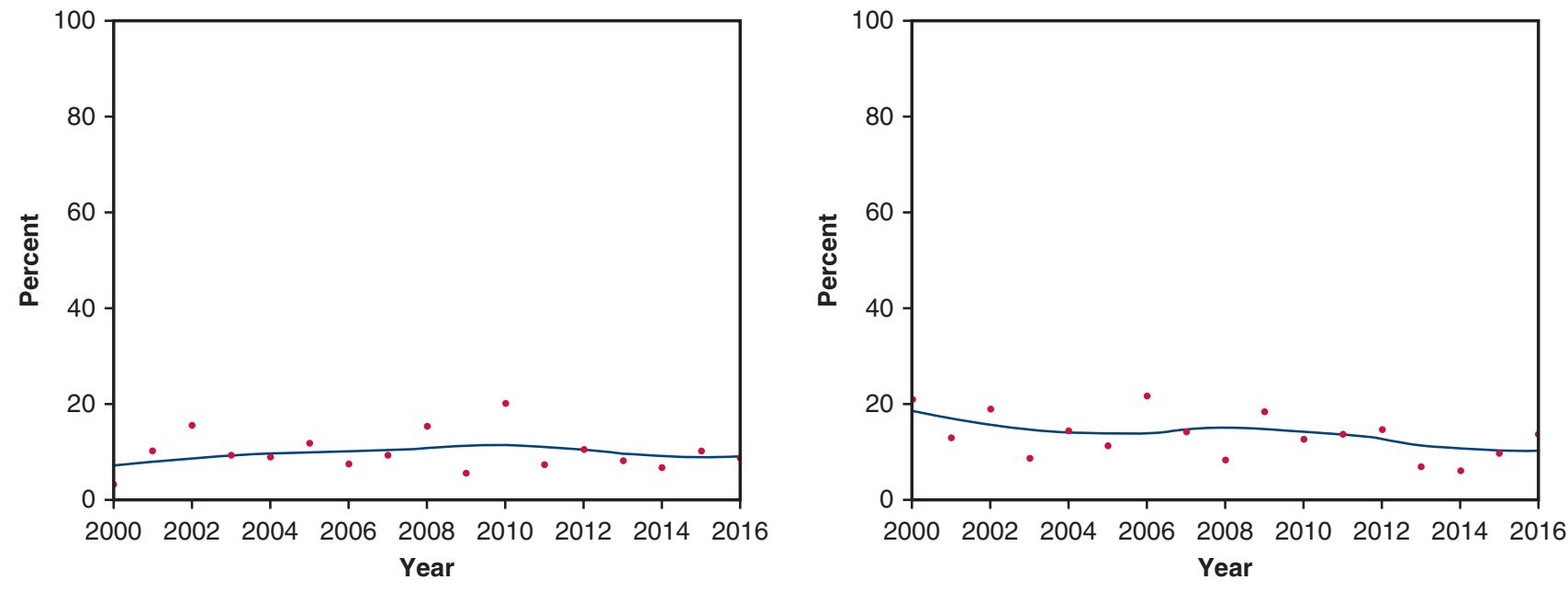

C

D

FIGURE E1. Temporal trend in in-hospital mortality and morbidity after acute type A dissection repair stratified by initial cannulation site. Solid lines are smoothing spline curves, and symbols represent percentage of patients with stated cannulation site each year. A, Hospital death. B, Stroke. C, Renal failure requiring dialysis (overall). D, Respiratory failure requiring tracheostomy (overall). 
TABLE E1. Variables considered in multivariable analyses

\section{Variables}

\begin{tabular}{|c|c|}
\hline Demographics & $\begin{array}{l}\text { Sex, race, or ethnicity (white, black, other), age }(\mathrm{y}) \text {, height }(\mathrm{cm}) \text {, weight }(\mathrm{kg}) \text {, body mass index }\left(\mathrm{kg} / \mathrm{m}^{2}\right) \text {, body surface area } \\
\left(\mathrm{m}^{2}\right) \text {, weight to height ratio }\end{array}$ \\
\hline Presenting symptoms & $\begin{array}{l}\text { New York Heart Association functional class (I-IV), time from symptom onset to operation (days), limb ischemia, } \\
\text { shortness of breath, bowel ischemia, new-onset renal failure, stroke or transient ischemic attack, syncope, limb } \\
\text { weakness, paresthesia }\end{array}$ \\
\hline $\begin{array}{l}\text { Preoperative hemodynamic } \\
\text { instability }\end{array}$ & $\begin{array}{l}\text { Any hemodynamic instability, new-onset heart failure or shock, cardiac arrest, aortic rupture, tamponade, pericardial } \\
\text { effusion }\end{array}$ \\
\hline Urgency & Emergency surgery \\
\hline Aortic pathology & $\begin{array}{l}\text { DeBakey type I dissection, DeBakey type II dissection, iatrogenic dissection, intraoperative iatrogenic dissection, } \\
\text { bicuspid aortic valve, connective tissue disorder }\end{array}$ \\
\hline Cardiovascular comorbidity & $\begin{array}{l}\text { Coronary artery disease, baseline aortic valve regurgitation severity, baseline aortic valve stenosis, baseline mitral valve } \\
\text { regurgitation severity, baseline mitral valve stenosis, baseline pulmonary valve regurgitation severity, baseline tricuspid } \\
\text { valve regurgitation severity, atrial fibrillation, ventricular arrhythmia, previous cardiac surgery, previous myocardial } \\
\text { infarction, left ventricular ejection fraction (\%), peripheral arterial disease, previous stroke or transient ischemic attack, } \\
\text { heart failure, hypertension }\end{array}$ \\
\hline Noncardiac comorbidity & $\begin{array}{l}\text { Diabetes mellitus, history of smoking, chronic obstructive pulmonary disease, preoperative dialysis, cancer, bilirubin } \\
(\mathrm{mg} / \mathrm{dL}) \text {, creatinine }(\mathrm{mg} / \mathrm{dL}) \text {, creatinine clearance }(\mathrm{mg} / \mathrm{dL}) \text {, glomerular filtration rate (modification of diet in renal } \\
\text { disease }\left(\mathrm{mL} / \mathrm{min} / 1.73 \mathrm{~m}^{2}\right) \text {, blood urea nitrogen }(\mathrm{mg} / \mathrm{dL}) \text {, hematocrit }(\%) \text {, hyperlipidemia, history of dementia, history } \\
\text { of cocaine use }\end{array}$ \\
\hline Procedure & $\begin{array}{l}\text { Cannulation: initial cannulation group, cannulation path (axillary maintained, femoral to central, femoral maintained, } \\
\text { central maintained), shift in cannulation, root replacement, root remodeling/repair, aortic valve resuspension, ascending } \\
\text { aorta repair, ascending aorta replacement, hemiarch, total arch, conventional elephant trunk and frozen elephant trunk, } \\
\text { retrograde brain perfusion, antegrade brain perfusion } \\
\text { Concomitant procedures: aortic valve repair, aortic valve replacement, coronary artery bypass grafting } \\
\text { Support: myocardial ischemic time (minutes), cardiopulmonary bypass time (minutes), and total circulatory arrest time } \\
\text { (minutes) }\end{array}$ \\
\hline Experience & Interval from start of study (January 1,2012 ) to index procedure \\
\hline
\end{tabular}

TABLE E2. Indications against initial axillary cannulation

\begin{tabular}{lccc}
\hline \multicolumn{1}{c}{ Indication } & & \multicolumn{2}{c}{ Cannulation site } \\
\cline { 2 - 3 } Unsuitable axillary & Total $(\mathbf{n}=\mathbf{1 5 8})$ & Central (n= 65 [41\%]) & Femoral (n= 93 [59\%]) \\
$\quad$ Dissected or thinned & $67(42)$ & $17(26)$ & $50(54)$ \\
$\quad$ Obesity & $56(35)$ & $14(22)$ & $42(45)$ \\
Surgeon preference & $11(7.0)$ & $3(4.6)$ & $8(8.6)$ \\
Hemodynamic instability & $38(24)$ & $23(35)$ & $15(16)$ \\
Previously cannulated & $34(22)$ & $9(14)$ & $25(27)$ \\
$\quad$ Intraoperative iatrogenic dissection & $19(12)$ & $16(25)$ & $3(3.2)$ \\
ECMO & $18(11)$ & $16(25)$ & $2(2.2)$ \\
\hline
\end{tabular}

Data are presented as No. (\%). ECMO, Extracorporeal membrane oxygenation. 
TABLE E3. Patient characteristics with and without intraoperative cannulation shifting

\begin{tabular}{|c|c|c|c|c|c|}
\hline \multirow[b]{2}{*}{ Characteristic } & \multicolumn{2}{|c|}{ Without shifting $(n=693)$} & \multicolumn{2}{|c|}{ With shifting $(\mathbf{n}=\mathbf{8 2})$} & \multirow[b]{2}{*}{$P$ value } \\
\hline & $\mathbf{n}^{*}$ & No. $(\%)$ or mean \pm SD & $\overline{\mathbf{n}^{*}}$ & No. $(\%)$ or mean \pm SD & \\
\hline \multicolumn{6}{|l|}{ Demographics } \\
\hline Age, y & 693 & $61 \pm 14$ & 82 & $64 \pm 14$ & .06 \\
\hline Male & 693 & $438(63)$ & 82 & $50(61)$ & .7 \\
\hline \multicolumn{6}{|l|}{ Race } \\
\hline Black & 687 & $149(22)$ & 80 & $15(19)$ & .5 \\
\hline White & 687 & $503(73)$ & 80 & $63(79)$ & .3 \\
\hline Other & 687 & $34(4.9)$ & 80 & $2(2.5)$ & .3 \\
\hline Body mass index $\left(\mathrm{kg} / \mathrm{m}^{2}\right)$ & 681 & $29 \pm 6.6$ & 80 & $29 \pm 5.6$ & .9 \\
\hline \multicolumn{6}{|l|}{ Extent of dissection } \\
\hline DeBakey type I & 693 & $593(86)$ & 82 & $74(90)$ & .2 \\
\hline DeBakey type II & 693 & $93(13)$ & 82 & $7(8.5)$ & .2 \\
\hline \multicolumn{6}{|l|}{ Presentation } \\
\hline Preoperative aortic valve regurgitation & 693 & $390(56)$ & 82 & $56(68)$ & .04 \\
\hline Pericardial effusion & 693 & $269(39)$ & 82 & $42(51)$ & .03 \\
\hline Hemodynamic instability & 693 & 119 (17) & 82 & $25(30)$ & .003 \\
\hline Tamponade & 693 & $68(9.8)$ & 82 & $20(24)$ & $<.0001$ \\
\hline Aortic rupture & 693 & $58(8.4)$ & 82 & $14(17)$ & .01 \\
\hline Preoperative limb weakness & 693 & $64(9.2)$ & 82 & $12(15)$ & .12 \\
\hline New-onset renal failure & 680 & $43(6.3)$ & 81 & $5(6.2)$ & $>.9$ \\
\hline Preoperative stroke or TIA & 693 & $30(4.3)$ & 82 & $6(7.3)$ & .2 \\
\hline New-onset heart failure or shock & 693 & $22(3.2)$ & 82 & $10(12)$ & .0001 \\
\hline Cardiac arrest & 693 & $17(2.5)$ & 82 & $5(6.1)$ & .06 \\
\hline Bowel ischemia & 680 & $14(2.1)$ & 81 & $6(7.4)$ & .004 \\
\hline \multicolumn{6}{|l|}{ Cardiovascular comorbidities } \\
\hline Connective tissue disorder & 693 & $23(3.3)$ & 82 & $1(1.2)$ & .3 \\
\hline Bicuspid aortic valve & 693 & $48(6.9)$ & 82 & $1(1.2)$ & .04 \\
\hline Preoperative aortic valve stenosis & 693 & $77(11)$ & 82 & $11(13)$ & .5 \\
\hline Previous cardiovascular surgery & 693 & $112(16)$ & 82 & $6(7.3)$ & .04 \\
\hline Hypertension & 692 & $592(86)$ & 82 & $65(79)$ & .13 \\
\hline Previous myocardial infarction & 693 & $126(18)$ & 82 & $13(16)$ & .6 \\
\hline Peripheral arterial disease & 693 & $83(12)$ & 82 & $8(9.8)$ & .6 \\
\hline \multicolumn{6}{|l|}{ Noncardiovascular comorbidities } \\
\hline Pharmacologically treated diabetes & 670 & $50(7.5)$ & 78 & $5(6.4)$ & .7 \\
\hline COPD & 693 & $78(11)$ & 82 & $11(13)$ & 6 \\
\hline Smoking history & 661 & $397(60)$ & 71 & $38(54)$ & .3 \\
\hline Previous stroke & 689 & $72(10)$ & 81 & $12(15)$ & .2 \\
\hline
\end{tabular}

$S D$, Standard deviation; TIA, transient ischemic attack; COPD, chronic obstructive pulmonary disease. *Patients with data available. 
TABLE E4. Intraoperative characteristics: without and with intraoperative cannulation shifting

\begin{tabular}{|c|c|c|c|c|c|}
\hline \multirow[b]{2}{*}{ Characteristic } & \multicolumn{2}{|c|}{ Without shifting $(n=693)$} & \multicolumn{2}{|c|}{ With shifting $(n=82)$} & \multirow[b]{2}{*}{$P$ value } \\
\hline & $\mathbf{n}^{*}$ & Value & $\mathbf{n}^{*}$ & Value & \\
\hline Extended repair & 693 & $170(24)$ & 82 & $8(9.8)$ & .003 \\
\hline Aortic valve replacement & 693 & 179 (26) & 82 & $27(33)$ & .17 \\
\hline Aortic valve resuspension & 693 & $285(41)$ & 82 & $37(45)$ & .5 \\
\hline Aortic valve repair & 693 & $43(6.2)$ & 82 & $2(2.4)$ & .17 \\
\hline Root replacement & 693 & $146(21)$ & 82 & $19(23)$ & .7 \\
\hline $\begin{array}{l}\text { Circulatory arrest } \\
\text { Total circulatory arrest time, } \min \dagger\end{array}$ & $\begin{array}{l}693 \\
662\end{array}$ & $\begin{array}{r}662(96) \\
0 / 20 / 36\end{array}$ & $\begin{array}{l}82 \\
80\end{array}$ & $\begin{array}{l}82(100) \\
9.4 / 24 / 35\end{array}$ & $\begin{array}{l}.05 \\
.06\end{array}$ \\
\hline Brain perfusion & 693 & $506(73)$ & 82 & $74(90)$ & .0007 \\
\hline Retrograde & 693 & $434(63)$ & 82 & $71(87)$ & $<.0001$ \\
\hline Antegrade & 693 & $55(7.9)$ & 82 & $3(3.7)$ & .16 \\
\hline Antegrade and retrograde & 693 & $15(2.2)$ & 82 & $0(0)$ & .18 \\
\hline CABG & 693 & 135 (19) & 82 & $15(18)$ & .8 \\
\hline Total myocardial ischemic time, min & 687 & $93 \pm 46$ & 81 & $94 \pm 50$ & .9 \\
\hline Total CPB time, min & 693 & $157 \pm 58$ & 82 & $160 \pm 67$ & .4 \\
\hline
\end{tabular}

Data are presented as No. (\%) or mean \pm standard deviation except where otherwise noted. $C A B G$, Coronary artery bypass grafting; $C P B$, cardiopulmonary bypass. *Patients with data available. $\nmid 15$ th $/ 50$ th $/ 85$ th percentiles.

TABLE E5. Risk factors associated with postoperative stroke

\begin{tabular}{|c|c|c|c|}
\hline Risk factor & Estimate $\pm \mathbf{S E}$ & $P$ value & Reliability, \%* \\
\hline Smaller body mass index $\dagger$ & $-1.6 \pm 0.68$ & .02 & 71 \\
\hline Aortic valve stenosis & $0.85 \pm 0.34$ & .01 & 71 \\
\hline No hyperlipidemia & $-0.80 \pm 0.29$ & .006 & 73 \\
\hline No root replacement & $-0.91 \pm 0.42$ & .03 & 67 \\
\hline Initial central cannulation without shifting and without brain perfusion $\ddagger$ & $1.1 \pm 0.54$ & .04 & - \\
\hline Initial central cannulation without shifting and with brain perfusion $\S$ & $0.57 \pm 0.57$ & .3 & - \\
\hline
\end{tabular}

$S E$, Standard error. *Proportion of 1000 bootstrap models in which variable appeared with $P \leq .05 . \dagger \operatorname{Ln}$ (body mass index), natural logarithmic transformation. $\ddagger$ Forced into model; $\mathrm{n}=5$. $\S$ Forced into model; $\mathrm{n}=4$.

TABLE E6. Outcomes in patients with hemodynamic instability

\begin{tabular}{|c|c|c|c|c|}
\hline \multirow[b]{2}{*}{ Outcome } & \multicolumn{3}{|c|}{ Initial cannulation site } & \multirow[b]{2}{*}{$P$ value } \\
\hline & Axillary $(n=89)$ & Central $(n=21)$ & Femoral $(n=34)$ & \\
\hline Hospital death & $19(21)$ & $5(24)$ & $13(38)$ & .16 \\
\hline Stroke & $8(9.0)$ & $4(19)$ & $3(8.8)$ & .4 \\
\hline Disabling stroke & $8(9.0)$ & $4(19)$ & $3(8.8)$ & .4 \\
\hline Renal failure requiring dialysis* & $19(22)$ & $5(24)$ & $9(26)$ & .9 \\
\hline Spinal cord infarction & $2(2.2)$ & $0(0)$ & $0(0)$ & .5 \\
\hline Respiratory failure requiring tracheostomy & $18(20)$ & $4(19)$ & $5(15)$ & .8 \\
\hline Bowel ischemia & $3(3.4)$ & $1(4.8)$ & $2(5.9)$ & .8 \\
\hline Reoperation for bleeding & $18(20)$ & $3(14)$ & $7(21)$ & .8 \\
\hline ICU length of stay, $\mathrm{h} \dagger$ & $44 / 190 / 624$ & $38 / 99 / 568$ & $24 / 86 / 593$ & .13 \\
\hline Postoperative length of stay, $\mathrm{d} \dagger$ & $5.4 / 14 / 33$ & $4.8 / 11 / 31$ & $2.8 / 9.0 / 28$ & .02 \\
\hline
\end{tabular}

Data are presented as No. (\%) except where otherwise noted. ICU, Intensive care unit. *Data available for 87 patients. $\dagger 15$ th/50th/85th percentiles. 
TABLE E7. Outcomes without and with intraoperative cannulation shifting

\begin{tabular}{|c|c|c|c|c|c|}
\hline \multirow[b]{2}{*}{ Outcome } & \multicolumn{2}{|c|}{ Without shifting $(n=693)$} & \multicolumn{2}{|c|}{ With shifting $(n=82)$} & \multirow[b]{2}{*}{$P$ value } \\
\hline & $\mathbf{n}^{*}$ & Value & $\mathbf{n}^{*}$ & Value & \\
\hline Hospital death & 693 & $56(8.1)$ & 82 & $11(13)$ & .10 \\
\hline Stroke & 693 & $57(8.2)$ & 82 & $7(8.5)$ & .9 \\
\hline Disabling stroke & 693 & $35(5.1)$ & 82 & $6(7.3)$ & .4 \\
\hline Renal failure requiring dialysis & 679 & $64(9.4)$ & 81 & $9(11)$ & 6 \\
\hline Spinal cord infarction & 693 & $5(0.72)$ & 82 & $0(0)$ & .4 \\
\hline Respiratory failure requiring tracheostomy & 693 & $89(13)$ & 82 & $15(18)$ & .17 \\
\hline Bowel ischemia & 693 & $14(2.0)$ & 82 & $1(1.2)$ & 6 \\
\hline Reoperation for bleeding & 693 & $60(8.7)$ & 82 & $9(11)$ & .5 \\
\hline ICU length of stay, $\mathrm{h} \dagger$ & 693 & $40 / 96 / 354$ & 82 & $30 / 87 / 564$ & .7 \\
\hline Postoperative length of stay, $\mathrm{d} \dagger$ & 693 & $6.2 / 10 / 24$ & 82 & $5.8 / 9.5 / 27$ & .7 \\
\hline
\end{tabular}

Data are presented as No. (\%) except where otherwise noted. $I C U$, Intensive care unit. *Patients with data available. $\dagger 15$ th/50th/85th percentiles.

TABLE E8. Outcomes: initial femoral cannulation without and with intraoperative cannulation shifting to central cannulation

\begin{tabular}{|c|c|c|c|}
\hline Outcome & Without shifting $(n=39)$ & With shifting $(\mathrm{n}=52)$ & $P$ value \\
\hline Hospital death & $6(15)$ & $8(15)$ & $>.9$ \\
\hline Stroke & $5(13)$ & $3(5.8)$ & .2 \\
\hline Disabling stroke & $3(7.7)$ & $3(5.8)$ & .7 \\
\hline Renal failure requiring dialysis & $6(15)$ & $5(9.6)$ & .4 \\
\hline Spinal cord infarction & $0(0)$ & $0(0)$ & $>.9$ \\
\hline Respiratory failure requiring tracheostomy & $7(18)$ & $10(19)$ & .9 \\
\hline Bowel ischemia & $1(2.6)$ & $0(0)$ & .2 \\
\hline Reoperation for bleeding & $6(15)$ & $4(7.7)$ & .2 \\
\hline ICU length of stay, $\mathrm{h}^{*}$ & $53 / 144 / 337$ & $24 / 83 / 503$ & .07 \\
\hline Postoperative length of stay, $d^{*}$ & $6.8 / 11 / 28$ & $5.1 / 9.1 / 27$ & .2 \\
\hline
\end{tabular}

Data are presented as No. (\%) except where otherwise noted. $I C U$, Intensive care unit. *15th/50th/85th percentiles. 